\title{
BRIEF
}

\section{Evaluating Pharmacy Faculty's Awareness of Teaching and Learning Myths and Misconceptions}

\author{
Melissa S. Medina, EdD, ${ }^{\mathrm{a}, \mathrm{b}}$ Ashley N. Castleberry, PharmD, MEd, ${ }^{\mathrm{c}}$ Adam Persky, PhD ${ }^{\mathrm{b}, \mathrm{d}}$ \\ ${ }^{\text {a }}$ University of Oklahoma Health Sciences Center, College of Pharmacy, Oklahoma City, Oklahoma \\ ${ }^{\mathrm{b}}$ Associate Editor, American Journal of Pharmaceutical Education, Arlington, Virginia \\ ${ }^{\mathrm{c}}$ University of Texas at Austin, College of Pharmacy, Austin, Texas \\ ${ }^{\mathrm{d}}$ University of North Carolina, Eshelman School of Pharmacy, Chapel Hill, North Carolina
}

Corresponding Author: Ashley N. Castleberry, University of Texas at Austin, College of Pharmacy, 2409 University Ave., Austin, TX 78712-1113. Tel: 512-232-3494. Email: ashley.castleberry@ austin.utexas.edu

Submitted June 1, 2021; accepted December 7, 2021; ePublished December 2021

Objective. To assess pharmacy faculty's knowledge of prominent and prevalent teaching and learning myths and misconceptions and evidence-based strategies prior to training.

Methods. Participants completed a baseline assessment containing 16 true/false knowledge questions over teaching and learning misconceptions (10) and myths (6), one open-ended application question, and four participant demographic questions including years of experience in pharmacy academia, the focus of their institution (teaching or research), the number of education meetings attended, and if they had formal training in education. After completing the baseline assessment of the top 16 misconceptions and myths, faculty were trained on the top 10 evidence-based teaching and learning strategies. At session completion, faculty were provided the assessment answers and scored their original responses.

Results. Results from the survey revealed that most responders (56\%) had been in academics between one and 10 years and attended two to 10 education meetings $(62 \%)$. The majority of participants worked at teaching-intensive universities $(56 \%)$ and most had no formal training in teaching (65\%). The average score on the assessment was $43 \%$ for the myths section versus $70 \%$ for the misconceptions section $(p<.001)$. Faculty participants were overconfident in their predictions (Predicted $=74 \%$, Actual $=60 \%$ ). Faculty demographics did not influence the assessment scores.

Conclusion. Pharmacy faculty may not know which teaching and learning strategies are evidence-based and which are myths or misconceptions. In addition, they are likely to be overconfident in their knowledge of this evidence. This provides opportunity for faculty development in these areas.

Keywords: learning myths, evidence-based education, faculty development

\section{INTRODUCTION}

Educational misconceptions and myths can be inadvertently embedded into the teaching practices of pharmacy faculty. ${ }^{1}$ These myths and misconceptions originate from sources such as opinions, observations of other teachers, personal experience, and the media. They can be grounded in "it worked for me as a student", "don't fix what isn't broken", or "that's how it has always been done". Regardless of the source or justification, educational myths and misconceptions can be damaging to teaching and learning. ${ }^{1}$ Take the common teaching aphorism, "those who can do, those who can't, teach." 2 This century-old saying is grounded in opinion, but has perpetuated as myth that disparages teachers and can underlie policies and practices related to teaching. ${ }^{1}$ Yet as research has shown, the best way to learn something is to teach it, "to teach is to learn"; "those who understand, teach". ${ }^{1,3}$ Believing the above myth may cause one to reject the use of peer teaching as a strategy for helping students become self-aware and self-directed learners and reflective practitioners, which are important pharmacy education outcomes. ${ }^{3,4}$ Unfortunately, not all faculty are aware of teaching myths and misconceptions, especially if they have not been specifically addressed and debunked during resident or graduate student teaching certificate programs or professional development workshops.

To date, there are no studies that evaluate pharmacy faculty members' beliefs of common teaching myths and misconceptions or their knowledge of conventional evidence-based teaching and learning strategies. Evaluating faculty's teaching knowledge and beliefs can help them more intentionally select their future professional development to address their knowledge deficits and weaknesses. This study was designed to assess pharmacy faculty's knowledge of ten misconceptions about evidence-based teaching and learning strategies and six teaching myths prior to training on these topics. The top 10 evidence-based teaching and learning strategies (activating prior knowledge, feedback, elaboration, 
scaffolding, testing, personalization, spacing, metacognition, distinctiveness, and peer teaching) were selected from the educational literature. ${ }^{5-9} 10$

\section{METHODS}

This study was conducted with a convenience sample at a session at the 2019 annual meeting of the American Association of Colleges of Pharmacy. Two hundred copies of a handout and survey were provided to attendees. The exact number of participants at the session was unable to be captured. The first page of the handout asked attendees to complete a 16-item baseline assessment and provide some demographic information (Tables 1 and 2). This baseline assessment contained 10 true/false questions pertaining to misconceptions and the related content of the presentation and six true/false questions on myths about teaching and learning (see Table 2). Participants were also asked to predict their score before starting the baseline assessment. After completion, participants engaged in one hour of instruction and activities delivered by the investigators related to the top 10 teaching and learning strategies. The length of the session did not allow for instruction related to the six teaching myths. The assessment was collected at the end of the session. The study received institutional review board approval (IRB\#12984).

Data were summarized using descriptive statistics. A one-way ANOVA with Tukey's post-hoc was used to analyze data based on baseline differences in demographics. Two metacognitive measures were calculated. The first was bias which is the difference between participant predicted score and their actual score and measures degree of over- or under-confidence. ${ }^{11}$. The second measure is absolute bias or the absolute value of the bias score; this measures accuracy or how close the predicted score was to the actual score. Statistical significance was set at $p<.05$.

\section{RESULTS}

A total of 80 participants completed the survey. Demographics of the responders can be found in Table 1. Most responders have been in academics between one and 10 years (56\%) and have been to two to 10 AACP annual meetings (62\%). The majority came from teaching-intensive universities (56\%) and most have had no formal training in teaching $(65 \%)$. When comparing performance on the knowledge portion, there were no differences based on length in academia, number of AACP meetings attended, type of university they are currently working in, or if they have formal educational training.

The assessment included 10 misconception questions related to knowledge of the top 10 evidence-based teaching strategies in addition to six questions about learning myths. The average score on the assessment was $43 \%$ for the myths section versus $70 \%$ for the misconceptions section $(p<.001)$. See Table 2 for individual item results.

We also examined the bias which compares the predicted score to the actual score and indicates over- or underconfidence. In general, responders were overconfident in their predictions of their overall score (predicted $=74 \%$, actual $=$ 60\%; range: 19 to 51\%). There were no significant differences within years in academia, number of AACP meetings attended, institution type, or whether participants had formal training. We next examined the absolute bias which assesses metacognitive accuracy. Here, participants were relatively inaccurate showing on average a 16-point difference between predicted scores and actual scores (range: 0 to $51 \%$ ).

\section{DISCUSSION}

The purpose of this study was to capture participants' knowledge about evidence-based teaching and learning misconceptions and myths in a population of faculty attending a national conference on teaching. We found that session attendees had moderately high knowledge about evidence-based strategies but poor knowledge about learning myths. Knowledge of these topics was not influenced by time in academia, the number of AACP meetings attended, the type of institution participants were from, or if they had some degree of teacher training.

Six of the ten misconceptions about evidence-based teaching strategies had average scores greater than $80 \%$ indicating participants had common knowledge around these topics (Scaffolding, 98\%; Personalization, 96\%; Retrieval, 91\%; Feedback, 90\%; Prior Knowledge, 89\%; and Collaborative Learning, 81\%). It is possible that faculty member's knowledge about these areas is the result of training since these are common areas of emphasis in teaching certificate programs and at the annual AACP meeting. Items with the lowest average scores were Contrast (61\%), Metacognition (36\%), Elaboration (35\%), and Spacing (25\%) indicating that participants would benefit from more development about these teaching and learning topics.

In addition to the questions about knowledge of the top 10 teaching and learning strategies, the assessment included six questions about learning myths. Scores on these items were significantly lower than the knowledge items (43\% versus $70 \%, p<.001)$. Myth questions included topics of the learning pyramid, learning styles, inquiry-based learning fits all, attention span, lecture is best, and hemispheric dominance. It is possible that participants answered these questions incorrectly because they see other faculty in their college using the strategy or they may have experienced the 
strategy in their own teaching. Relatedly, another reason could be that these myths are passed down from mentors to mentees during training, much like folklore. There is plenty of evidence that even teachers with formal training believe some of these myths. ${ }^{12}$ Despite the evidence suggesting otherwise, learning myths are also still present in research articles and presentations. Sometimes myths persist because people have difficulty judging what is true or false. We make these true/false judgments in several ways such as: accepting new information by default, accepting new information when it aligns with what we believe to be true, and accepting new information when it is repeated more often. ${ }^{13}$ As a result of these experiences, observations, mentoring, and training; people often mistake common practice for best practice. ${ }^{1}$ Furthermore, sometimes faculty reject new ideas because they contradict the status quo. ${ }^{1}$ Because of these reasons, changing teaching practice is challenging. If instructors hold on to these teaching myths, it may be difficult to design the most effective instruction.

Another finding of this study revealed that all respondents were overconfident in their understanding of these topics as indicated by their predictive scores being greater than their actual score. This could be due to the pervasive nature of teaching and learning myths, limited faculty development in these areas, reliance on past experience and previous practice, and/or personal biases. ${ }^{14}$ This could indicate that development is needed in these topics to ensure that evidence-based teaching and learning strategies are being used in our classrooms, labs, and experiential learning sites.

The strengths of this study were the sample were active pharmacy educators and the simplified assessment of knowledge. One of the limitations of this study is the convenience sampling of those that attended the specific session and that out of the 200+ attendees, not all participants completed the assessment. Those who attended the conference and this session specifically, may have a special interest in teaching since they pursued this development related to teaching and learning. Therefore, results may not be applicable for all pharmacy faculty as the sample did not fully represent pharmacy faculty as a whole. The exact number of participants at the session is unknown so the actual response rate is uncertain. However, the study did capture participants' demographics and this sample included faculty from different levels, programs, and years of experience. Additionally, there were a limited number of items assessing each strategy (one per item), and only certain strategies were sampled. Finally, the study was only designed to measure baseline misconceptions, myths, and knowledge, not long-term retention and/or application of what participants learned or remembered.

As with any training situation, assessing prior knowledge is useful in tailoring instruction and thus this approach may be useful as a screening tool for faculty development efforts at the local or national level. The results of this study suggest that faculty may need more educational opportunities around certain topics such as learning myths.

\section{CONCLUSION}

Pharmacy faculty may not know which teaching and learning strategies are evidence-based and which are myths. With limited time, they may not be able to gain development in these topics efficiently. In addition, they are likely to be overconfident in their knowledge of this evidence. Providing specific and concise faculty development in these areas, especially related to debunking educational myths, is warranted to promote evidence-based teaching practices to advance pharmacy education. As an academy, there can be better screening of conference proposals or manuscripts to prevent the spread of misinformation. Individuals have the responsibility to use evidence-based literature to inform their teaching practices. Instructors may use popular press books as justification as their evidence based for teaching, but these books are not peer reviewed and as such may be subject to misinformation. We encourage everyone to use the strongest evidence possible to support their instructional decisions, such as data from meta-analyses and systematic reviews, just as they would in clinical practice.

\section{REFERENCES}

1. Sauntson H. Twenty-seven educational myths and how to debunk them. https://teacherofsci.com/educationalmyths/. Accessed April 27, 2021.

2. Shaw GB. Man and Superman; 1903.

3. Ten Cate O, Durning S. Dimensions and psychology of peer teaching in medical education. Med Teach. 2007;29(6):546-52.

4. Medina MS, Plaza CM, Stowe CD, et al. Report of the 2012-2013 Academic Affairs Standing Committee: Revising the Center for the Advancement of Pharmacy Education (CAPE) Educational Outcomes 2013. Am J Pharm Educ. 2013;77(8):1.

5. Applying the Science of Learning in Education: American Psychological Association.

6. The Science of Learning: Deans for Impact.

7. Learning about learning: National Council on Teaching Quality; 2016. 
8. Dunlosky J, Rawson KA, Marsh EJ, Nathan MJ, Willingham DT. Improving Students' Learning With Effective Learning Techniques: Promising Directions From Cognitive and Educational Psychology. Psychol Sci Public Interest. 2013;14(1):4-58.

9. Weinstein Y, Madan CR, Sumeracki MA. Teaching the science of learning. Cog Res Princp Impl. 2018;3(1):1-17.

10. Hattie J, Yates G. Visible learning and the science of how we learn. London; New York: Routledge, Taylor \& Francis Group; 2014.

11. Rivers ML, Dunlosky J, Persky AM. Measuring Metacognitive Knowledge, Monitoring, and Control in the Pharmacy Classroom and Experiential Settings. Am J Pharm Educ. 2020;84(5):7730-.

12. Krammer G, Vogel SE, Grabner RH. Believing in Neuromyths Makes Neither a Bad Nor Good Student-Teacher: The Relationship between Neuromyths and Academic Achievement in Teacher Education. 2021;15(1):54-60.

13. Brashier NM, Marsh EJ. Judging Truth. Ann Rev Psychol. 2020;71(1):499-515.

14. Kruger J, Dunning D. Unskilled and Unaware of It: How Difficulties in Recognizing One's Own Incompetence Lead to Inflated Self-Assessments. J Personal Soc Psychol. 1999;77(6):1121-34.

15. Brod G, Werkle-Bergner M, Lee Shing Y. The influence of prior knowledge on memory: A developmental cognitive neuroscience perspective. Front Behav Neurosci. 2013;7:139-.

16. Boud D, Molloy E. Rethinking models of feedback for learning: the challenge of design. Assess Eval High Educ. 2013;38(6):698-712.

17. Kelley CM, McLaughlin AC. Individual Differences in the Benefits of Feedback for Learning. Human Fact. 2012;54(1):26-35.

18. Bisra K, Liu Q, Nesbit JC, Salimi F, Winne PH. Inducing Self-Explanation: a Meta-Analysis. Educ Psychol Rev. 2018;30(3):703-25.

19. Bock DD, Deprez J, Dooren WV, Roelens M, Verschaffel L. Abstract or Concrete Examples in Learning Mathematics? A Replication and Elaboration of Kaminski, Sloutsky, and Heckler's Study. J Res Math Educ. 2011;42(2):109-26.

20. Lyons K, McLaughlin JE, Khanova J, Roth MT. Cognitive apprenticeship in health sciences education: a qualitative review. Adv Health Sci Educ. 2017;22(3):723-39.

21. Reiser BJ, Tabak I. Scaffolding. In: Sawyer RK, ed. The Cambridge Handbook of the Learning Sciences. 2 ed. Cambridge: Cambridge University Press; 2014:44-62.

22. Yang BW, Razo J, Persky AM. Using Testing as a Learning Tool. Am J Pharm Educ. 2019;83(9):1862-72.

23. Adesope OO, Trevisan DA, Sundararajan N. Rethinking the Use of Tests: A Meta-Analysis of Practice Testing. Rev Educ Res. 2017;87(3):659-701.

24. Rowland CA. The Effect of Testing Versus Restudy on Retention: A Meta-Analytic Review of the Testing Effect. Psychol Bull. 2014;140(6):1432-63.

25. Gillihan SJ, Farah MJ. Is Self Special? A Critical Review of Evidence From Experimental Psychology and Cognitive Neuroscience. Psychol Bull. 2005;131(1):76-97.

26. Canning EA, Harackiewicz JM, Priniski SJ, Hecht CA, Tibbetts Y, Hyde JS. Improving Performance and Retention in Introductory Biology With a Utility-Value Intervention. J Educ Psychol. 2018;110(6):834-49.

27. Carpenter SK, Cepeda NJ, Rohrer D, Sean HKK, Pashler H. Using Spacing to Enhance Diverse Forms of Learning: Review of Recent Research and Implications for Instruction. Educ Psychol Rev. 2012;24(3):369-78.

28. Cepeda NJ, Pashler H, Vul E, Wixted JT, Rohrer D. Distributed Practice in Verbal Recall Tasks: A Review and Quantitative Synthesis. Psychol Bull. 2006;132(3):354-80.

29. Donovan JJ, Radosevich DJ. A Meta-Analytic Review of the Distribution of Practice Effect: Now You See It, Now You Don't. J Appl Psychol. 1999;84(5):795-805.

30. Hartwig MK, Was CA, Isaacson RM, Dunlosky J. General knowledge monitoring as a predictor of in-class exam performance: General knowledge monitoring. Br J Educ Psychol. 2012;82(3):456-68.

31. Hacker DJ, Bol L, Horgan DD, Rakow EA. Test Prediction and Performance in a Classroom Context. $J$ Educ Psychol. 2000;92(1):160-70.

32. Tversky A. Features of similarity. Psychol Bull. 1977;84(4):327-52.

33. Johnson MK, Hasher L. Human learning and memory. Ann Rev Psychol. 1987;38(1):631-68.

34. Kyndt E, Raes E, Lismont B, Timmers F, Cascallar E, Dochy F. A meta-analysis of the effects of face-to-face cooperative learning. Do recent studies falsify or verify earlier findings? Educ Res Rev. 2013;10:133-49.

35. Crouch CH, Mazur E. Peer Instruction: Ten years of experience and results. Am J Physics. 2001;69(9):970-7.

36. Letrud K, Hernes S. The diffusion of the learning pyramid myths in academia: An exploratory study. J Curricul Stud. 2016;48(3):291-302. 
37. Grospietsch F, Mayer J. Pre-service Science Teachers' Neuroscience Literacy: Neuromyths and a Professional Understanding of Learning and Memory. Front Human Neurosci. 2019;13:20-.

38. Torrijos-Muelas M, Gonzalez-Villora S, Bodoque-Osma AR. The Persistence of Neuromyths in the Educational Settings: A Systematic Review. Front Psychol. 2021;11:591923-.

39. Masters K. Edgar Dale's Pyramid of Learning in medical education: Further expansion of the myth. Med Educ. 2020;54(1):22-32.

40. Pashler H, McDaniel M, Rohrer D, Bjork R. Learning Styles: Concepts and Evidence. Psychol Sci Public Interest. 2008;9(3):105-19.

41. Coffield F, Moseley D, Hall E, Ecclestone K. Learning styles and pedagogy inpost-16 learning: A systematic and critical review. . London: Learning \& Skills Research Centre; 2004.

42. Kirschner PA, Sweller J, Clark RE. Why Minimal Guidance During Instruction Does Not Work: An Analysis of the Failure of Constructivist, Discovery, Problem-Based, Experiential, and Inquiry-Based Teaching. Educ Psychol. 2006;41(2):75-86.

43. Bradbury NA. Attention span during lectures: 8 seconds, 10 minutes, or more? Adv Physiol Educ. 2016;40(4):509-13.

44. Csikszentmihalyi M, Csikszentmihalyi IS. Optimal experience : psychological studies of flow in consciousness. Cambridge ; New York: Cambridge University Press; 1988.

45. Fredrickson BL, Branigan C. Positive emotions broaden the scope of attention and thought-action repertoires. Cogn Emot. 2005;19(3):313-32.

46. Shapiro KL, Raymond JE, Arnell KM. The attentional blink. Trend Cogn Sci. 1997;1(8):291-6.

47. Willems C, Martens S. Time to see the bigger picture: Individual differences in the attentional blink. Psychonom Bull Rev. 2016;23(5):1289-99.

48. Matheson C. The educational value and effectiveness of lectures. Clin Teach. 2008;5(4):218-21.

49. Huggins CM, Stamatel JP. An Exploratory Study Comparing the Effectiveness of Lecturing versus Team-based Learning. Teach Sociol. 2015;43(3):227-35.

50. Lindell AK, Kidd E. Why Right-Brain Teaching is Half-Witted: A Critique of the Misapplication of Neuroscience to Education. Mind Brain Educ. 2011;5(3):121-7. 
Table 1. Summary of score comparisons by demographics

\begin{tabular}{|c|c|c|c|c|c|c|c|}
\hline Metric & Number (\%) & $\begin{array}{l}\text { Predicted Score } \\
\text { Average (SD) }\end{array}$ & $\begin{array}{l}\text { Score } \\
\text { Average (SD) }\end{array}$ & $\begin{array}{l}\text { Misconceptions } \\
\text { Section Average (SD) }\end{array}$ & $\begin{array}{l}\text { Myths } \\
\text { Section Average (SD) }\end{array}$ & Bias & $\begin{array}{l}\text { Absolute } \\
\text { Bias }\end{array}$ \\
\hline Overall & $80(100 \%)$ & $74(12)$ & $60(11)$ & $70(14)$ & $44(21)$ & $14(15)$ & $16(12)$ \\
\hline \multicolumn{8}{|l|}{ Length in Academia } \\
\hline$<$ 1year & $5(6)$ & $74(10)$ & $61(7)$ & $66(17)$ & $53(30)$ & $12(7)$ & $12(7)$ \\
\hline $1-5$ years & $24(30)$ & $73(11)$ & $61(11)$ & $70(12)$ & $46(22)$ & $14(16)$ & $15(13)$ \\
\hline $6-10$ years & $21(26)$ & $73(15)$ & $57(13)$ & $66(15)$ & $41(20$ & $11(15)$ & $19(15)$ \\
\hline$>10$ year & $20(25)$ & $76(12)$ & $62(11)$ & $76(12)$ & $38(16)$ & $17(18)$ & $18(11)$ \\
\hline No Answer & $10(13)$ & $74(11)$ & $63(11)$ & $70(17)$ & $50(21)$ & $11(6)$ & $11(6)$ \\
\hline \multicolumn{8}{|c|}{ Number of AACP Meetings } \\
\hline 1 & $16(20)$ & $76(9)$ & $57(11)$ & $63(14)$ & $48(21)$ & $18(12)$ & $18(12)$ \\
\hline 2 to 5 & $39(49)$ & $72(12)$ & $61(12)$ & $72(12)$ & $42(23)$ & $11(16)$ & $15(13)$ \\
\hline 6 to 10 & $10(13)$ & $72(15)$ & $61(12)$ & $70(14)$ & $47(11)$ & $11(17)$ & $17(11)$ \\
\hline$>10$ & $9(11)$ & $81(9)$ & $60(6)$ & $77(7)$ & $32(13)$ & $20(14)$ & $20(14)$ \\
\hline No Answer & $6(8)$ & $74(14)$ & $63(13)$ & $68(22)$ & $53(20$ & $12(6)$ & $12(6)$ \\
\hline \multicolumn{8}{|l|}{ Institution } \\
\hline Balanced & $15(19)$ & $72(13)$ & $56(13)$ & $67(17)$ & $38(16)$ & $15(18)$ & $18(15)$ \\
\hline Research-Intensive & $11(14)$ & $74(12)$ & $64(11)$ & $67(16)$ & $58(25)$ & $8(21)$ & $15(16)$ \\
\hline Teaching Intensive & $45(56)$ & $73(11)$ & $60(10)$ & $72(11)$ & $41(20)$ & $15(14)$ & $17(11)$ \\
\hline No Answer & $9(11)$ & $74(12)$ & $62(11)$ & $70(18)$ & $48(22)$ & $11(7)$ & $16(11)$ \\
\hline \multicolumn{8}{|c|}{ Formal Teaching Training } \\
\hline Yes & $19(24)$ & $75(11)$ & $60(14)$ & $66(16)$ & $50(25)$ & $14(18)$ & $17(15)$ \\
\hline No & $52(65)$ & $74(12)$ & $60(10)$ & $71(12)$ & $40(18)$ & $14(15)$ & $16(12)$ \\
\hline
\end{tabular}


Table 2. List of question topics with performance, their respective category, and references

$\begin{array}{llll}\text { Question \# } & \begin{array}{l}\text { Average } \\ \text { Percent }\end{array} & \text { Misconceptions and Myths } & \text { Evidence-based Teaching and Learning } \\ & \text { correct } & & \text { Reality }\end{array}$

$199 \quad$ Misconception: Prior Knowledge ${ }^{15}$

If students are unprepared for class (i.e., do not do prior reading), taking a quiz on their baseline knowledge and understanding does not help them learn.
Misconception: Feedback ${ }^{16}$

When providing feedback, the most important aspect is letting the student know if their answer was correct or incorrect.

Misconception: Elaboration ${ }^{18}$

When learning new content, it is helpful to associate it with information already recorded in short term memory

Misconception: Scaffolding 20

For novice learners, breaking down tasks to component pieces doesn't improve learning outcomes.

\section{Misconception: Retrieval ${ }^{22}$}

After reading and studying a chapter of text, research has shown re-reading and restudying that chapter is better than taking a practice test (i.e., restudy $>$ practice test)

\section{Misconception: Personalization ${ }^{25}$}

Learning is not improved by having students state why what they are learning is important to them.

\section{Misconception: Spacing ${ }^{27}$}

Cramming (practicing all that once) before an exam results in lower examination grades than distributing practice over the days preceding the exam.
Anything that helps activate prior knowledge can facilitate learning. We learn by connecting new learning to previously learned material. ${ }^{15}$

Appropriate feedback involves informing the learner what is correct or incorrect, why the answer is correct or incorrect and where they can go for more practice.

Knowing answers are correct or incorrect is not as helpful as knowing the why. ${ }^{16,17}$

Concrete information is better remembered than abstract and we learn better when we tie new learning to prior learned material (in long-term storage). In general, it is hard for us to learn abstract ideas, we do better with concrete examples; thus, we must relate the abstract idea to a concrete example or experience. $^{18,19}$

Working memory is limited. If too much information is presented at once, the amount of information will exceed our working memory. Scaffolding allows students to learn pieces of the bigger puzzle one at a time, so they are less likely to overwhelm their working memory. ${ }^{20,21}$

When we retrieve information from memory, that piece of information is placed into our memory's workbench, and new "tags" are placed on that information, strengthening the memory. Testing helps consolidate knowledge and skills and helps ensure information is accessible when it is needed to solve a problem. ${ }^{22-24}$

It is important for students to make personal connections to material - why is it important for them to learn this material? ${ }^{10,26}$

Studying the day before an exam (cramming) can lead to high performance on an exam. But that does not mean it is learned well. We have to differentiate between information that is easily accessible and information that is stored well in memory. Cramming leads to high accessibility but poor storage. Spacing of practice increases the ability to store 
Misconception: Contrast ${ }^{32}$

Students will learn more when finding the similarities between individual beta-blockers than finding their distinctive qualities

\section{Myth: Learning Styles ${ }^{12,37,38,40}$}

Misconception: Collaborative Learning ${ }^{34}$ Students teaching other students in an interdependent way is an ineffective learning strategy with small effect sizes.

Myth: Learning Pyramid ${ }^{12,36-38}$

People generally remember most of what they read.

Individuals learn better when they receive information in their preferred learning style (for example, visual, auditory or kinesthetic)

Myth: Inquiry-based Learning ${ }^{12,37,38,42}$ Minimal guidance during the instruction (e.g., problem-based learning, inquiry-based learning) is largely effective for novice to intermediate learners. information for longer periods of time. ${ }^{27-}$

Humans are generally poor at judging their abilities. A student can have high confidence but perform poorly (overconfident) and a student can have low confidence and perform well (underconfident). However, higher performing students tend to be better judges of their knowledge than lower performing students. ${ }^{30,31}$

Research shows that participants learn more when they are looking for differences between concepts. Deep levels of processing encourage recall because of distinctiveness (stimulus is different from other memory traces) and elaboration (extracting meaning and interconnecting concepts). ${ }^{32,33}$

Peer-instruction falls under the category of cooperative or collaborative learning. It first requires students to do individual work, then to work with peers in an interdependent manner. Effect sizes compared to other instructional approaches can be large. ${ }^{34,35}$

The learning pyramid or cone of learning has a long history. In essence, it suggests people learn $10 \%$ of what they read, $20 \%$ of what they hear, $30 \%$ of what they see, and $90 \%$ of what they do. However, there is no data to support these numbers. ${ }^{36,39}$

Learning styles have persisted in education for decades. Learning styles suggest that a learner with a keenness for visual information will do better (learn more) when presented with visual information. This is called "meshing" but has not been proven in research. Additionally, characterizing learning styles is full of issues with validity and reliability. ${ }^{40,41}$

Minimal guidance instruction is not effective for everyone. Novice or intermediate students may struggle in such environments. Novices benefit from things like worked examples, that are much more support than minimal guidance. Minimal guidance may work better for individuals that have appropriate background knowledge and know where to find appropriate information. ${ }^{42}$

Attention span is context dependent. 
Human attention is about 8-10 minutes; thus, we need to design classes in short chunks.

\begin{abstract}
Myth: Lecture Ineffectiveness ${ }^{48}$ Lecture is an ineffective instructional strategy.
\end{abstract}

Myth: Left vs. Right Brain 12, 37, 38, 50 Differences in hemispheric dominance (left brain or right brain) can help to explain individual differences amongst learners.
Some classroom research suggests it is about 10 minutes based on note density and heart rate. However, we can be distracted by things around us (attentional blink), pay attention for very long periods of time when motivated (flow), have reduced attention when hungry or increased attention when in a positive mood. And if we talk about attention at the physiological level, it can take seconds to deplete neurotransmitters which impact attention. ${ }^{43-47}$

Lecture is an effective instructional strategy depending on the context being used, just like any other strategy. It is an efficient and effective way to provide information to students and can be effectively used as pre-class preparation or for a "time for telling" during a case discussion. ${ }^{48,49}$

There is a popular myth among educators that traditional learning favors the left hemisphere (the "academic" brain) and neglects the right hemisphere (the "creative" or "artistic" brain), When performing any task "everything in the brain (is) in flux - both sides, the front and back, the top and bottom to think that you could reduce this to a simple leftright dichotomy would be misleading and oversimplified" 50 